Article

\title{
On the Relationship between Holocene Geomorphic Evolution of Rivers and Prehistoric Settlements Distribution in the Songshan Mountain Region of China
}

\author{
Peng Lu ${ }^{1,2, *}$, Duowen Mo ${ }^{3}$, Hui Wang ${ }^{4}$, Ruixia Yang ${ }^{1,2,5}$, Yan Tian ${ }^{1}$, Panpan Chen ${ }^{1}$, \\ Rosa Lasaponara ${ }^{1,6}$ and Nicola Masini ${ }^{1,7}$
}

1 Institute of Geography, Henan Academy of Sciences, Zhengzhou 450052, China; yangrx@radi.ac.cn (R.Y.); qingcheng1981@163.com (Y.T.); cppbed@163.com (P.C.); rosa.lasaponara@imaa.cnr.it (R.L.); nicola.masini@gmail.com (N.M.)

2 Zhengzhou Base, International Center on Space Technologies for Natural and Cultural Heritage under the Auspices of UNESCO, Zhengzhou 450052, China

3 College of Urban and Environmental Sciences, Peking University, Beijing 100871, China; dmo@urban.pku.edu.cn

4 The Institute of Archaeology, Chinese Academy of Social Sciences, Beijing 100710, China; wh@cass.org.cn

5 Key Laboratory of Digital Earth Science, Institute of Remote Sensing and Digital Earth, Chinese Academy of Sciences, Beijing 100094, China

6 Institute of Methodologies for Environmental Analysis, National Research Council C.da Santa Loja, 85050 Tito Scalo (PZ), Italy

7 Institute for Archaeological and Architectural Heritage, National Research Council C.da Santa Loja, 85050 Tito Scalo (PZ), Italy

* Correspondence: bulate_0@163.com

Academic Editor: Marc A. Rosen

Received: 12 September 2016; Accepted: 10 January 2017; Published: 13 January 2017

\begin{abstract}
This paper deals with the study of Holocene geomorphic evolution of rivers around Songshan Mountain in relation to human frequentation in Prehistoric periods. The investigations were performed by means of an integration of GIS data processing; field surveys and particle size analysis. In 8000-3000 aBP; in the Songshan Mountain Region, large-scale river sedimentation occurred. This increased the elevation of river beds that were higher than today. After $3000 \mathrm{aBP}$; the upper reaches of the rivers experienced a down cut; while the lower reaches experienced continuing sedimentation. The data on the elevation of prehistoric settlements above the river levels were obtained from Digital Elevation Models (DEMs). These data were corrected according to the evolutionary features of fluvial landforms in order to obtain synchronous elevations above river levels of prehistoric settlements. The relationship between sediment distribution and the Holocene geomorphic evolution was investigated through the statistical analysis of the elevation above the river levels. Outputs from our analyses enabled us to differentiate three evolutionary stages. During the first one, related to Peiligang culture (9000-7500 aBP), populations mainly settled on both hilly relief and high plateaus depending on their agriculture production modes. During the second stage, from Yangshao (7500-5000 aBP) to the Longshan period (5000-4000 aBP), settlements were mainly distributed on mountainous areas and hilly lands to avoid flooding and to develop agriculture. Finally, during the Xiashang culture (4000-3000 aBP), a large number of settlements migrated to the plain area to facilitate trade of goods and cultural exchanges.
\end{abstract}

Keywords: Songshan Mountain; Holocene; geomorphic evolution of rivers; elevation above river level; prehistoric settlements; temporal and spatial distribution 


\section{Introduction}

The spatial distribution of prehistoric settlements is generally closely connected with fluvial landforms, as confirmed by many studies all over the world [1,2]. The relationship between spatio-temporal distribution of prehistoric settlements and fluvial landforms has received considerable attention by many scholars [3-8]. For example, in the Colorado River Corridor, many remnants of past human activity are situated within or on top of fine-grained sediment deposits derived from the river [9]. These archaeological sites are susceptible to degradation over time, due to natural weathering and erosion as well as to anthropogenic impacts $[10,11]$. However, fluvial landforms since the Holocene have been in constant evolution, presenting different features contrasting the current situation [12,13].

Therefore, it is expected that significant changes occurred in fluvial landform and, in turn, environmental conditions strongly influenced human settlement distribution, paleodemographic variability and social interactions. For these reasons, studies on the spatial and temporal distribution of prehistoric settlements must take into account the synchronic features between landscape and human occupation patterns. In order to enrich this analysis as much as possible, spatial analyses and remote sensing $[14,15]$ can be fruitfully used to support the investigations on settlement distribution.

This study deals with GIS-based analyses performed on geomorphic evolution and changes throughout the Holocene of the rivers in the Songshan Mountain Region of China. It is an emblematic area in Central China, for which the geomorphic evolution of Holocene rivers had repercussions on the distribution and organization of the prehistoric settlements. Since ancient times, Chinese culture developed with unity and continuity for thousands of years [16]. Obviously, environmental conditions played an important role, especially in this region [17]. Today, the influence of these important factors in the cultural evolution of Central China remains unknown.

In this study, the prehistoric settlement patterns have been reconstructed in a synchronous way with respect to their geomorphic context. The elevation above the river levels of prehistoric settlements at that time is obtained. The pattern and evolution of the spatial and temporal distribution of prehistoric settlements under the influence of fluvial landform evolution have been analyzed through a co-occurrence statistical analysis. The hypothesis is that the settlements favored hilly lands at levels which allowed an easy access to river resources while at the same time, minimizing the problem of flooding danger. The relationships between prehistoric settlement locations and the Holocene fluvial landform evolution have been evaluated, in order to better understand potential interactions between palaeo-environment and palaeo-culture in the region. Our results also provide a reference to understand the influential factors which contributed to continuity and unity of the Central China culture.

\section{Research Area}

The study area is located in the hinterlands of Central China, with Songshan Mountain as the core; it includes Zhengzhou, Luoyang, Xuchang, Pingdingshan and the peripheral area (Figure 1).

The Songshan Mountain area inherited nearly all environmental and cultural features of Central China [18]. Its western part is adjacent to the Loess Plateau, and its Eastern part to the North China Plain. The terrain is higher in the west and lower in theEast, with the highest elevations exceeding $1500 \mathrm{~m}$ and the lowest elevations not reaching $100 \mathrm{~m}$ [19]. The regional macroscopic geomorphology frame formed from Himalayan tectonic movement (the Tertiary period). After that movement, the terrain fluctuation, mountain format and river trend of this area were generally formed. Then, the landform feature changed within a narrow range under the influence of climate change [20] and tectonic movement. River incision and aggradation are important factors of the landform change in the Holocene. The drainage basin is composed of several rivers and tributaries (see Figure 1) which in detail, are the Yellow River and its tributaries like Luohe River and Yihe River, which border the Northern side of the region, Yinghe River and its tributaries such as Jialuhe River, Shuangjihe River and Shahe River to the South and Northeast [21]. 
Prehistoric culture in this area inherited the evolutionary features of the Central Chinese culture. Peiligang culture (9000-7500 aBP), Yangshao culture (7000-5000 aBP), Longshan culture (5000-4000 aBP) and Xiashang culture (4000-3000 aBP) are in direct line of succession. They maintained an exact similar cultural character and continuously developed over thousands of years without interruption [22,23].

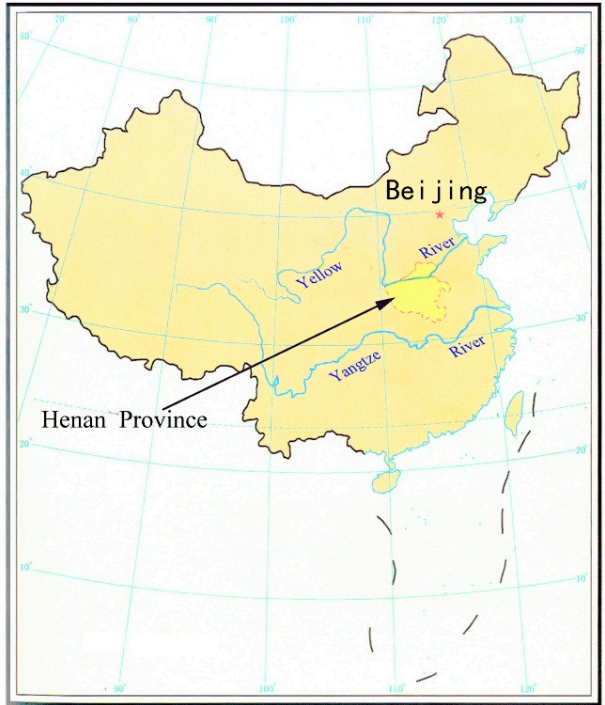

(a)

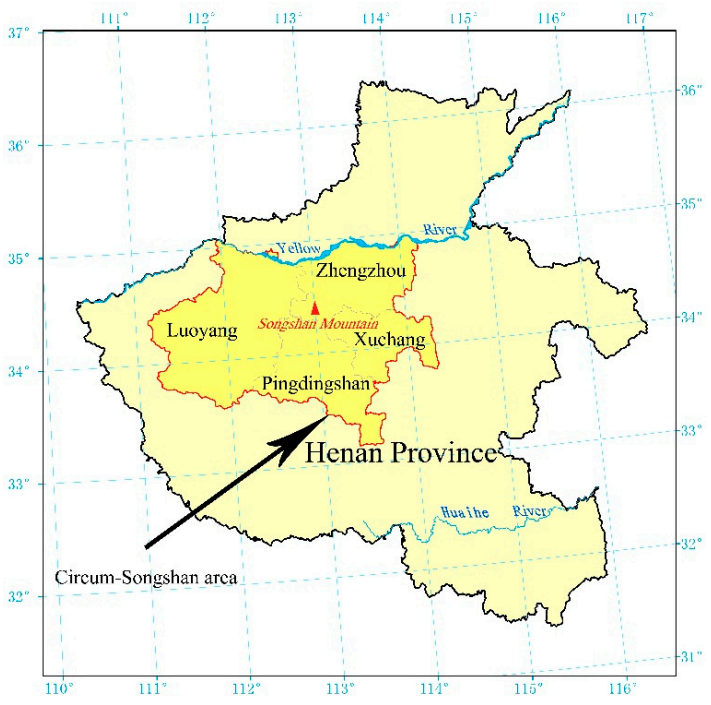

(b)

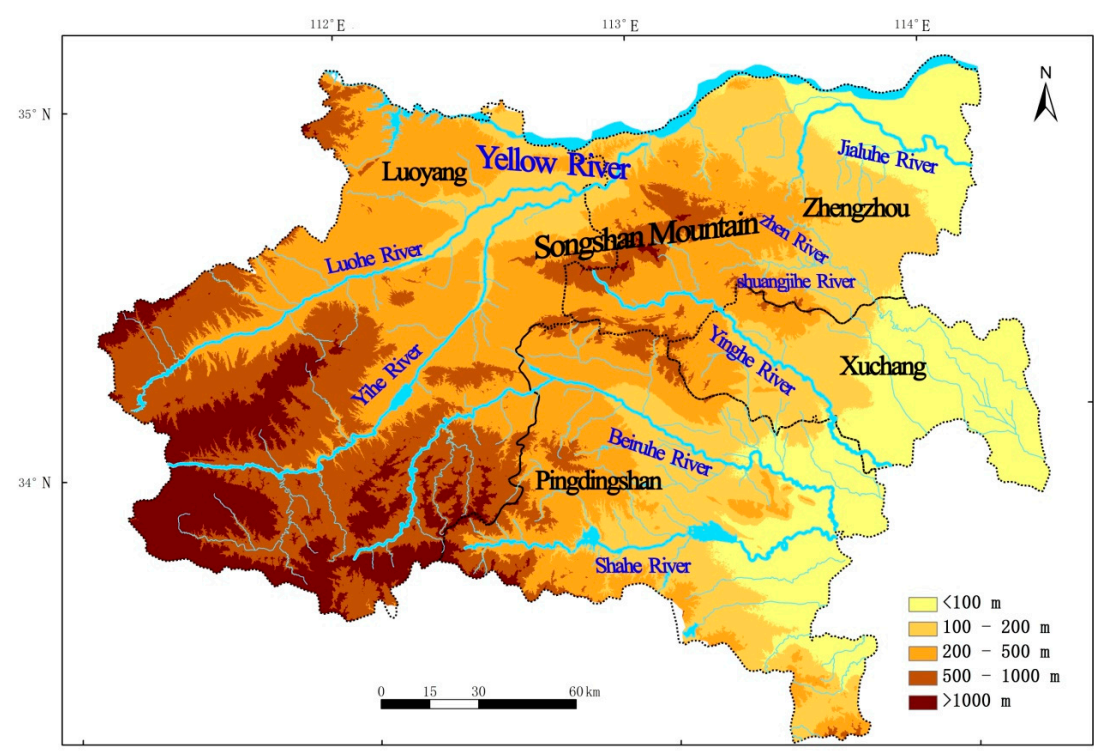

(c)

Figure 1. Study area (a) Location of Henan Province in China; (b) Location of Circum-Songshan area in Henan Province; (c) Location of and topography around Songshan Mountain.

\section{Data and Methods}

\subsection{Data}

The data used in this article fall into three categories, namely, DEM images, water system distribution maps and prehistoric settlement data. DEM images were obtained from the data of the SRTM (Shuttle Radar Topography Mission), which were jointly measured by NASA and the National Imagery and Mapping Agency (NIMA). The data version is V4.1, and the resolution is $90 \mathrm{~m}$. The water systems were extracted from 1:50,000 topographic maps. Remote sensing data (aerial image, 
satellite imagery of TM and Spot 5) and field surveys were used as supplementary data sources to interpret the regional geomorphic feature. The prehistoric settlement data were obtained from the latest archaeological surveys [24]. The position, size and age of settlements were recorded in detail during the surveys. These prehistoric settlements were marked on the maps by longitude and latitude coordinates to generate the distribution map. All data were subjected to uniform registration and calibration to render them uniform in mathematical information (Gauss $6^{\circ}$ projection). The central meridian is $114^{\circ}$. The registration method is counterpart point correction.

In particular, there were 73, 563, 660 and 634 settlements of Peiligang, Yangshao, Longshan and Xiashang cultures, respectively (Figure 2). The maps put in evidence significant changes in the human frequentation in the region of Songshan Mountain. In particular, the settlements are mostly located along and in the south of the Yellow River and in the drainage basin of the Jaluhe and Yinghe Rivers during Peiligang periods. In the Yanshao period, the settlements strongly increased. They were concentrated in the North of the region, mainly in the Yellow River drainage basin, around Luoyang, and to the east of the Songshan mountains and South of JaluheRiver, in particular around Zheng Zhou. In the Longshan period, the settlement pattern in the North seemed quite stable, whereas a slight increase in settlements occurred in the Southwest near the Yinghe, Beiruhe and Shahe Rivers. Finally, in the Xiashang period, two major clusters of settlements, one around Luoyang and another around Zhengzhou increased and developed [25].
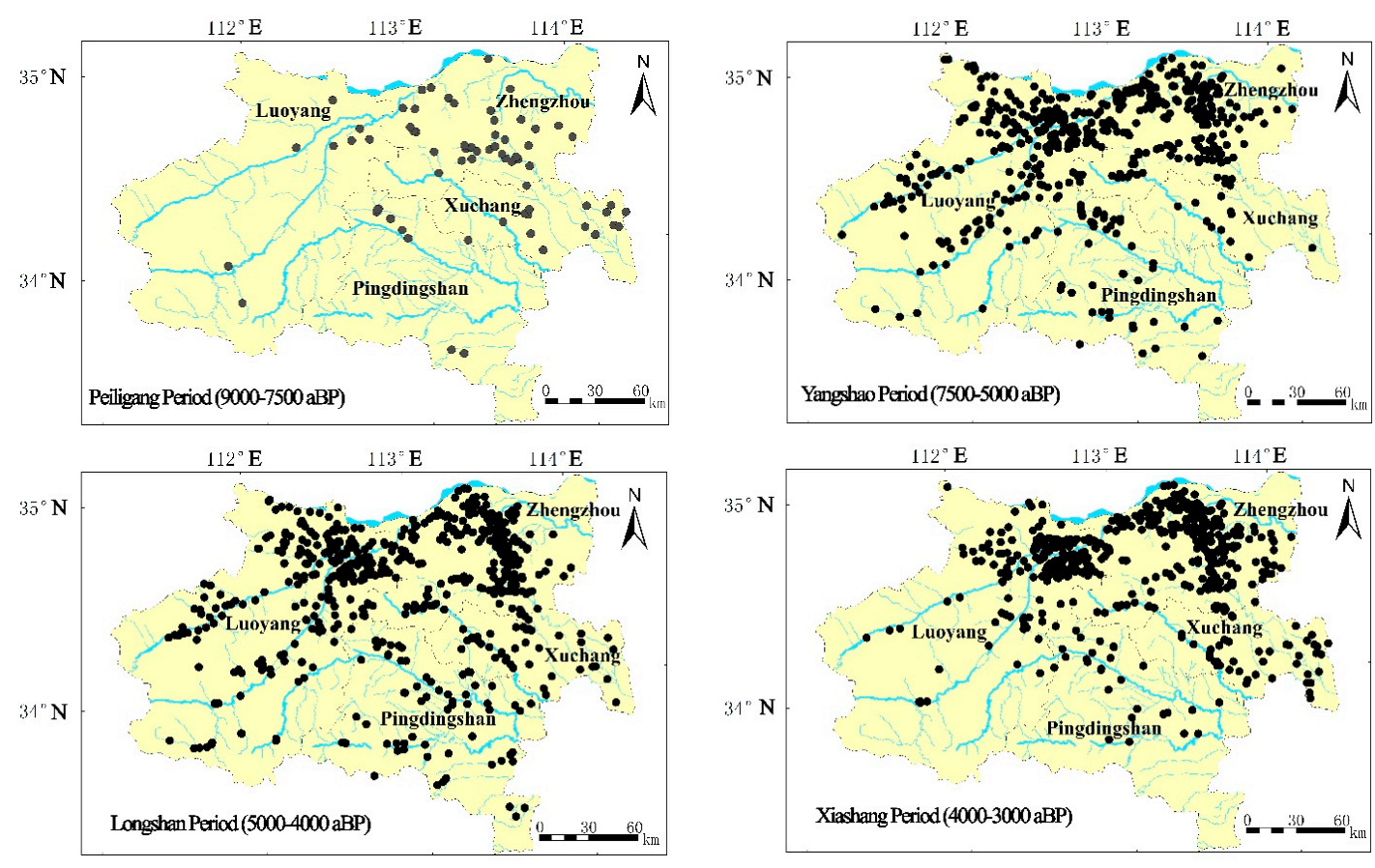

Figure 2. Distribution of prehistoric settlements around Songshan Mountain.

\subsection{Field Survey}

A detailed field survey was carried out in this region with respect to geomorphic pattern, morphology of each geomorphological unit, material composition, sedimentary type, stratigraphic age, and formation and evolutionary history of each geomorphic unit. The geomorphic features of the region were investigated, and the Holocene landforms of the region were recreated. The general framework of fluvial landform evolution was established.

\subsection{Experimental Analysis}

Based on the observation and analysis of Holocene stratigraphic sections for different geomorphic units, typical sections were selected to determine the lithology, thickness, sedimentary type and 
sediment bedding of each stratum. Samples of a typical profile and some supplementary profiles were analyzed in the laboratory for their chronology and grain size. A total of over 100 grain size and 10 chronology samples were examined. Sedimentary type, processes and dating were also determined.

\subsection{Acquisition of Data on Elevation of Settlements above River Level}

Water systems and distribution maps of prehistoric settlements were overlaid on DEM images by using ArcGIS (V 9.2, Esri, Redlands, CA, USA). The coordinates of points on the river system closest to the prehistoric settlements were calculated. The layer containing the closest point was generated. The elevations of settlements and river levels were obtained from DEM images. Finally, the data for elevation above river levels were obtained for the settlements. This is the elevation difference between the settlement and river level.

\subsection{Revision of Elevation above River Level}

The elevations above river levels obtained from DEM were modern data. They were greatly different from the ancient landforms for the river undercutting and depositing. Therefore, data correction was necessary according to the evolutionary features of fluvial landforms in order to obtain synchronous elevations above the river levels of prehistoric settlements. According to the results of field surveys and experimental analyses, the evolutionary features of Holocene fluvial landforms in different region were analyzed. The synchronous vertical distances from prehistoric settlements to river levels were calculated, and the differences from the modern values were compared. Using these differences, the elevations of each prehistoric settlement above the river levels in different regions were revised to obtain synchronous data.

\subsection{Statistical Analysis of Elevation above the River Level}

The corrected elevation of each prehistoric settlement above the river levels was input into Excel for statistical analysis. In addition, the number and proportions of settlements of Peiligang culture, Yangshao culture, Longshan culture and Xiashang culture distributed in plains or hilly lands in four different periods were calculated. Using a spatial statistical model, the number and proportion of settlements at different elevations above the river levels were also calculated for the four periods. These quantitative data provided information about the environmental orientation of settlement site selection and provided evidence in favor of the hypothesis that the settlements favored the hilly lands because of alternating downcutting and sedimentation events, at levels above the river ( 5 to $20 \mathrm{~m}$ ) in order to optimize the access to river resources and at the same time minimize the flooding risk.

Therefore, they were examined to determine the relationship between the distribution of prehistoric settlements and the evolution of fluvial landforms in the same region. Insight into the relationship between man and nature in prehistoric time was sought.

\section{Results and Discussion}

\subsection{Evolutionary Features of Holocene Fluvial Landforms}

On the whole, the terrain of the Songshan Mountain area is sloped from mountains in the middle to the peripheral plain. The middle mountain has the highest elevation, which exceeds $1000 \mathrm{~m}$. It is surrounded by low mountains (500-1000 m), followed by hills (200-500 m) and plains ( $200 \mathrm{~m})$ on the periphery (Figure 3). Between the plains and the mountainous region, including hilly lands, there is a tectonic transition belt. While the mountainous region and hilly lands have been continuously uplifted, the plain has experienced long-term subsidence [26]. Evidently, the mountainous region and hilly lands have a different evolutionary history of fluvial landforms. 


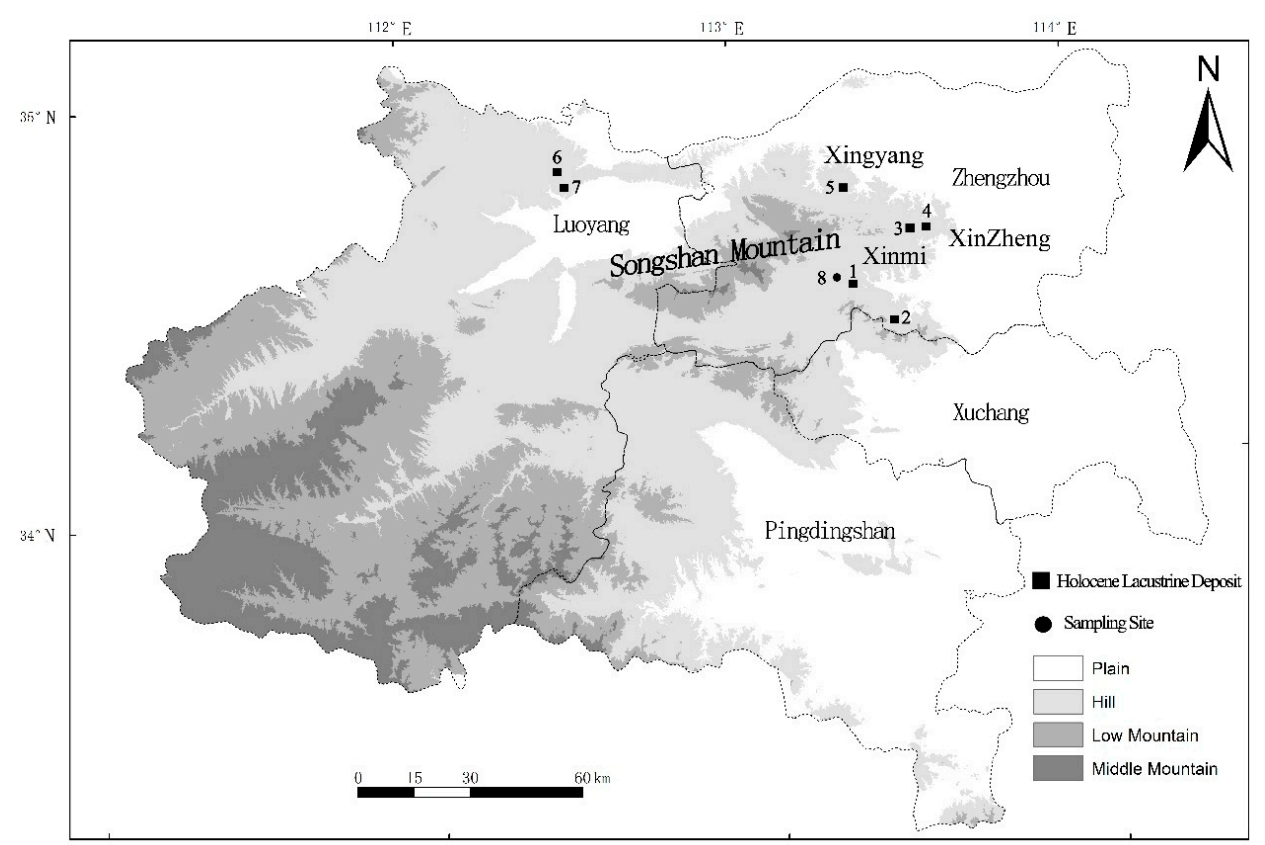

Figure 3. Sampling sites and the positions where the Holocene lacustrine deposits were found. 1 Quliang; 2 Tanghu; 3 Qiaogou; 4 Zhaizhai; 5 Zhangwuzhai; 6 Sihenan; 7 Baimasi; 8 Shiyuan (Sampling site).

The rivers in this area generally developed a multistage terrace (Figure 4). Stratigraphic sequences show that the secondary terrace was formed in the late Pleistocene to early Holocene; the primary terrace was formed in the late Holocene [27]. Field survey data indicate that the secondary terrace of the Zhen River (which is the secondary tributary of the Ying River, in Shiyuan Village, Quliang Town, Xinmi City $34^{\circ} 29.409^{\prime} \mathrm{N}, 113^{\circ} 36.933^{\prime} \mathrm{E}$ ) was found [28]. This site is located in the transition belt between piedmont hills to the river valley plain (Figure 3). The top of the terrace is nearly $15 \mathrm{~m}$ above the modern river level, with a typical topographic position. A Yangshao settlement was also found in this position. The layer of the Yangshao settlement was found to alternate with natural strata. The whole profile had a thickness of about $5 \mathrm{~m}$ and could be divided into five layers from top to bottom (see profile surveyed nearby Shiyuan village shown in Figure 5). The five layers are described as follows. Some samples have been dated using Accelerator Mass Spectrometry (AMS) ${ }^{14} \mathrm{C}$.

(1) Topsoil at $0.3 \mathrm{~m}$ characterized as tilled soil, loose texture, with large porosity and severe artificial disturbance.

(2) Recent loess soil at $0.4 \mathrm{~m}$ characterized as sandy loess, grayish yellow, uniform and loose texture, with a small amount of mycelia at the bottom (the bottom was dated by AMS ${ }^{14} \mathrm{C}$ as $2775 \pm 40 \mathrm{aBP}$ ).

(3) Weak palaeosol at $0.6 \mathrm{~m}$ with two sublayers. Upper sublayer: $0.2 \mathrm{~m}$, brown, containing a large amount of argillan and mycelia, and having dense texture (dated by AMS ${ }^{14} \mathrm{C}$ as $3330 \pm 40 \mathrm{aBP}$ ). Lower sublayer: $0.4 \mathrm{~m}$, maroon, dense and hard texture, with a large amount of mycelia and argillan (dated by AMS ${ }^{14} \mathrm{C}$ as $3560 \pm 40 \mathrm{aBP}$, corresponding to the Xiashang Period).

(4) Silt soil at $0.5 \mathrm{~m}$ characterized as grayish yellow, with obvious horizontal bedding, soft texture, but no dating. Its age was estimated by the dating data and sedimentation rate of the upper and lower layers at approximately 5000-4000 aBP, corresponding to the Longshan Period.

(5) Lacustrine deposit at $2.8 \mathrm{~m}$ outcrop. In the south, this is the layer corresponding to the Yangshao settlement. Both the lacustrine deposit and the layer of the Yangshao settlement are overlain by silt soil. This layer is subdivided into three sublayers. Upper sublayer: $0.5 \mathrm{~m}$, lacustrine deposit, clay, gray green, dated by AMS ${ }^{14} \mathrm{C}$ as $5455 \pm 40 \mathrm{aBP}$. Intermediate sublayer: $0.8 \mathrm{~m}$, alternating lacustrine deposit and secondary loess, clayey silt, light gray green, dated by AMS 
${ }^{14} \mathrm{C}$ as $7360 \pm 45 \mathrm{aBP}$. Lower sublayer: $1.5 \mathrm{~m}$, lacustrine deposit, clay, deep gray green, dated by AMS ${ }^{14} \mathrm{C}$ as $7800 \pm 60 \mathrm{aBP}$.

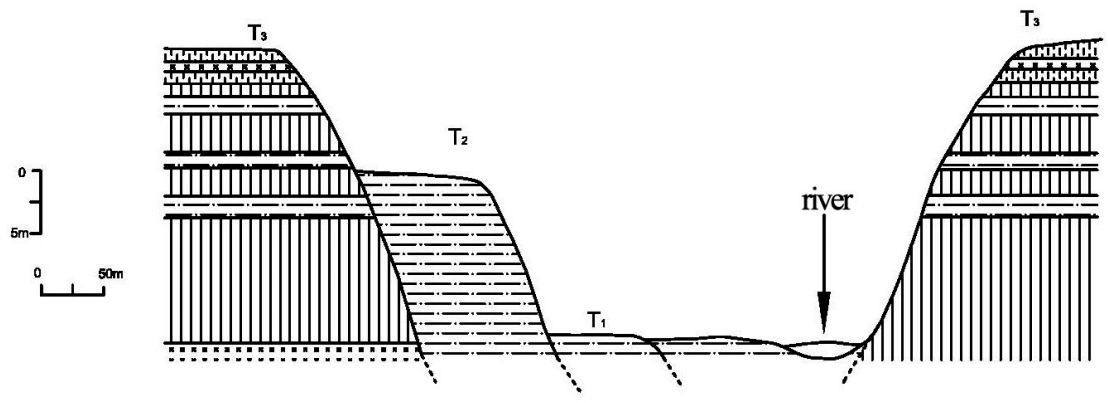

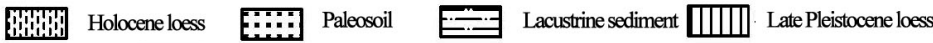

Figure 4. The cross-section of fluvial terraces in the Songshan area.

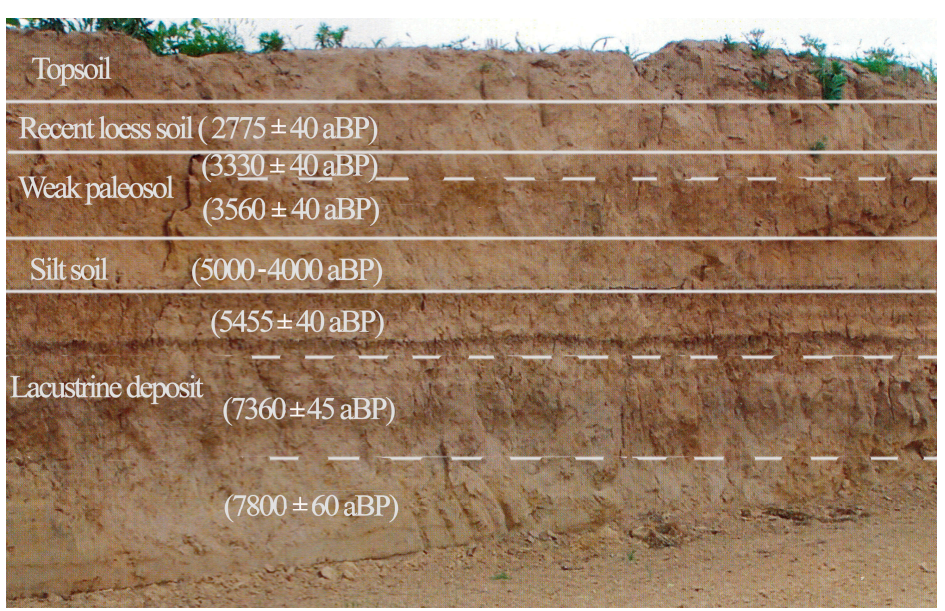

Figure 5. Stratigraphy of the Shiyuan Profile (sampling site, No. 8 in Figure 3).

Since the first layer is tilled soil with severe artificial disturbance, particle size analysis was only performed on the other layers. Several particle size parameters were analyzed. Mean particle size $\mathrm{Mz}$ $(\phi)$, sorting coefficient $S_{0}$, standard deviation $\sigma 1$, skewness $S_{k 1}$ and kurtosis $K_{G}$ served to characterize the particle size, sorting and distribution of soil [29]. The results of particle size analysis are shown in Table 1.

Table 1. Particle size analysis of Shiyuan Profile.

\begin{tabular}{cccccccc}
\hline Layer & Sublayer & Age (aBP) & $\mathbf{M z}(\boldsymbol{\phi})$ & $\mathbf{S}_{\mathbf{0}}$ & $\boldsymbol{\sigma}_{\mathbf{1}}$ & $\mathbf{S}_{\mathbf{k} \mathbf{1}}$ & $\mathbf{K}_{\mathbf{G}}$ \\
\hline Recent loess & & $2775 \pm 40$ & 4.87 & 4.94 & 1.65 & 0.24 & 0.95 \\
\hline Weak & Upper sublayer & $3330 \pm 40$ & 4.56 & 4.77 & 1.65 & 0.38 & 0.97 \\
palaeosol & Lower sublayer & $3560 \pm 40$ & 4.47 & 2.99 & 1.41 & 0.37 & 1.30 \\
\hline Silt soil & & $5000-4000$ & 4.04 & 2.51 & 1.22 & 0.33 & 1.48 \\
\hline \multirow{2}{*}{ Lacustrine } & Upper sublayer & $5455 \pm 40$ & 5.51 & 3.51 & 1.39 & 0.18 & 1.09 \\
deposit & Intermediate sublayer & $7360 \pm 45$ & 5.39 & 4.75 & 1.59 & 0.13 & 0.94 \\
& Lower sublayer & $7800 \pm 60$ & 4.99 & 5.33 & 1.71 & 0.15 & 0.94 \\
\hline
\end{tabular}

The results of particle size analysis indicated that the soil profile is dominated by silty sand. The lacustrine deposit at the bottom had a small particle size, with poor sorting and positive skewness, indicating that the sediments are composed mainly of coarse components, with medium kurtosis. 
The weak hydrodynamic conditions suggested that the rivers in the middle Holocene were in a relatively stable state, which lasted for quite some time. Although the silt soil sublayer was also dominated by silty sand, the particle size was greater than that of lacustrine deposit, with significantly high skewness. Moreover, its distribution range was larger than that of lacustrine deposit. In this period, the rivers were dominated by sedimentation on a large scale. After that, the regressive erosion of rivers began. Because of the higher terrain of the Shiyuan soil profile, the loess sediments were deposited. Loess sediments served as the parent material for the development of palaeosols under favorable climatic conditions.

The sedimentation process found in the Shiyuan soil profile is representative of the other sample sites in the Songshan Mountain area which also showed signs of this type of sedimentation (Figure 3).

In the Tanghu site (see 2 in Figure 3), located in the basin the secondary terrace of river, containing relics of the Longshan culture, had lacustrine deposit [30].

In Sihenan (see 6 in Figure 3), the relics were located in a tributary of Luo River. Therein, the secondary terrace of these relics had two periods of Holocene lacustrine deposit, which have been dated to 3755-4610 aBP and 5660-7020 aBP [31,32].

Finally, in other high hillocks or terraces of Zhengzhou, Xinmi, Xinzheng and Xingyang, Holocene lacustrine or paludal sediments have been found [33,34]. All these signs point to the fact that river sedimentation events in the middle Holocene possessed regional characteristics.

Thus, the Holocene geomorphic evolution of rivers includes the following features. From the end of the late Pleistocene to the early Holocene, obvious river downcutting occurred under a warmer climate and tectonic activities, which gave rise to the current secondary terrace. However, the amplitude of downcutting at that time was not significant, and the depth of the river valley was less than in the present day. In the middle Holocene (8500-3000 aBP), large-scale sedimentation occurred in the river basin probably due to the rising sea level or the stable tectonic activity of the region [35]. This sedimentation process affected the whole area. As a result, the river levels generally rose. From the elevation of gravel bed sediments of the middle Holocene in the Luohe area and alluvial deposits of the middle Holocene in Quliang relics in the Shuangjihe River basin, it can be inferred that the river levels at that time was about $10 \mathrm{~m}$ above the current river levels [36]. In the late Holocene after $3000 \mathrm{aBP}$, regional tectonic activities were aggravated, with uplifting of the middle and lower reaches. The river downcut the sediments of the middle Holocene by about $10 \mathrm{~m}$. As a result, the current primary terrace was formed in the middle and lower reaches. On the contrary, the lower reaches were located in the subsiding region and underwent sedimentation. It can be judged from the Holocene deposits drilled from Dahecun relics [37] that the sedimentation rate in the lower reaches was about $1 \mathrm{~mm} /$ year.

According to the analysis above, the prehistoric (9000-3000 aBP) fluvial landform of the Songshan Mountain area differed greatly from the current landform. At that time, the primary terrace seen today had not yet formed. The river levels in the middle and upper reaches was about $10 \mathrm{~m}$ higher than the current river level. Since the lower reaches underwent continuous sedimentation, the river levels at that time was lower by $3-5 \mathrm{~m}$ compared to the present day.

\subsection{Elevation of Prehistoric Settlements above River Level}

The elevations above the river levels extracted from DEM images reflect the current geomorphic features. To obtain synchronous elevations of prehistoric settlements above river level, it was necessary to correct the data for fluvial geomorphic evolution. Using the spatial location, the prehistoric settlements were divided into two categories, namely, those distributed in the mountainous region and hilly lands in the middle and upper reaches, and those in the plain in the lower reaches. In the period considered (9000-3000 aBP), the middle and upper reaches underwent continuous sedimentation. After $3000 \mathrm{aBP}$, large-scale river downcutting began, with an average amplitude of $10 \mathrm{~m}$. For this reason, in 9000-3000 aBP, the elevation of prehistoric settlements above the river levels was about $10 \mathrm{~m}$ lower than the present day elevation. Accordingly, the elevations above the river levels minus $10 \mathrm{~m}$ are the 
prehistoric values. The lower reaches underwent constant sedimentation at a rate of about $1 \mathrm{~mm} /$ year. Thus, the current values of elevation plus the corresponding thickness of sedimentation are the prehistoric values for settlements on the plain. The thickness added was $7 \mathrm{~m}, 5 \mathrm{~m}, 4 \mathrm{~m}$ and $3 \mathrm{~m}$ for the Peiligang settlement, Yangshao settlement, Longshan settlement and Xiashang settlement, respectively.

After applying the corrections, the prehistoric settlements were analyzed by geomorphic location and elevation above the river level. The results indicated that the prehistoric settlements of the Peiligang, Yangshao, Longshan and Xiashang culture were mostly distributed in the mountainous region and hilly lands (Table 2). The settlements of Peiligang and Xiashang culture located in the piedmont hills accounted for about $85 \%$ of the total, and the proportions in the Yangshao and Longshan periods were as high as $95 \%$. Two major features were identified with respect to the number of settlements. As for the total number of settlements, Peiligang culture had a far smaller number than the three later periods. The sharp rise in settlements from the Peiligang period to the Yangshao period was comparable to that in the three later periods. Also, the number of settlements in the Yangshao and Longshan periods was comparable, and there was a large increase in the number of settlements in the plain in the Xiashang period, with a slight difference in site selection.

Table 2. Geomorphic types of n. 1930 prehistoric settlements around Songshan Mountain.

\begin{tabular}{cccccc}
\hline & \multicolumn{2}{c}{$\begin{array}{c}\text { Settlements in Hilly Lands and } \\
\text { Mountainous Region } \mathbf{( 2 0 0 - 1 0 0 0 ~} \mathbf{~ m})\end{array}$} & Settlements on the Plain (<200 m) & \multirow{2}{*}{ Total } \\
\cline { 2 - 5 } & Number & Proportion & Number & Proportion & \\
\hline Peiligang & 61 & $84 \%$ & 12 & $16 \%$ & 73 \\
Yangshao & 527 & $94 \%$ & 36 & $6 \%$ & 563 \\
Longshan & 632 & $96 \%$ & 28 & $4 \%$ & 660 \\
Xiashang & 547 & $86 \%$ & 87 & $14 \%$ & 634 \\
\hline
\end{tabular}

The minimum elevations of settlements in Peiligang, Yangshao, Longshan and Xiashang culture were comparable, but the maximum values differed somewhat (Table 3). Peiligang settlements had the lowest maximum elevation, which was only $80 \mathrm{~m}$. The maximum elevations of the other three periods were all above $300 \mathrm{~m}$, reaching the height of hinterlands of the mountainous region or the top of low hills. As for the means, the values of the four periods were comparable, though there was a general downward trend over time. Quantitative statistics showed that the settlements with elevations of $5-10 \mathrm{~m}$ in the four periods comprised the largest proportion. The settlements with elevations of $5-40 \mathrm{~m}$ accounted for over $85 \%$ in each corresponding period (Figure 6). There were only three settlements in the Peiligang period with elevations of only $0-5 \mathrm{~m}$. This was the lowest number in the four periods. These low-elevation settlements only accounted for about $4 \%$ of all settlements in the four periods. The number of low-elevation settlements was comparable in the four periods, accounting for about $8 \%$ in each period. Settlements higher than $40 \mathrm{~m}$ reached the largest number in the Yangshao period, followed by the Longshan and Xiashang periods. Such settlements were the fewest in the Peiligang period, where the number was ten.

Table 3. River level-based elevations of prehistoric settlements around Songshan Mountain.

\begin{tabular}{|c|c|c|c|c|c|c|c|c|}
\hline & \multirow{2}{*}{$\operatorname{Min}(\mathrm{m})$} & \multirow{2}{*}{$\operatorname{Max}(\mathrm{m})$} & \multirow{2}{*}{ Mean (m) } & \multicolumn{5}{|c|}{ Quantitative Statistics } \\
\hline & & & & $0-5 \mathrm{~m}$ & 5-10 m & $10-20 \mathrm{~m}$ & $20-40 \mathrm{~m}$ & $>40 \mathrm{~m}$ \\
\hline Peiligang & 2 & 80 & 17 & $\begin{array}{c}3 \\
4.2 \%\end{array}$ & $\begin{array}{c}34 \\
47.2 \%\end{array}$ & $\begin{array}{c}11 \\
15.3 \%\end{array}$ & $\begin{array}{c}14 \\
19.4 \%\end{array}$ & $\begin{array}{c}10 \\
13.9 \%\end{array}$ \\
\hline Yangshao & 2 & 350 & 14 & $\begin{array}{c}44 \\
7.8 \%\end{array}$ & $\begin{array}{c}309 \\
54.9 \%\end{array}$ & $\begin{array}{c}122 \\
21.7 \%\end{array}$ & $\begin{array}{c}49 \\
8.7 \%\end{array}$ & $\begin{array}{c}39 \\
6.9 \%\end{array}$ \\
\hline Longshan & 2 & 350 & 10 & $\begin{array}{c}59 \\
8.9 \%\end{array}$ & $\begin{array}{c}437 \\
66.2 \%\end{array}$ & $\begin{array}{c}100 \\
15.2 \%\end{array}$ & $\begin{array}{c}41 \\
6.2 \%\end{array}$ & $\begin{array}{c}23 \\
3.5 \%\end{array}$ \\
\hline Xiashang & 2 & 320 & 9 & $\begin{array}{c}54 \\
8.5 \%\end{array}$ & $\begin{array}{c}467 \\
73.7 \%\end{array}$ & $\begin{array}{c}62 \\
9.8 \%\end{array}$ & $\begin{array}{c}35 \\
5.5 \%\end{array}$ & $\begin{array}{c}16 \\
2.5 \%\end{array}$ \\
\hline
\end{tabular}



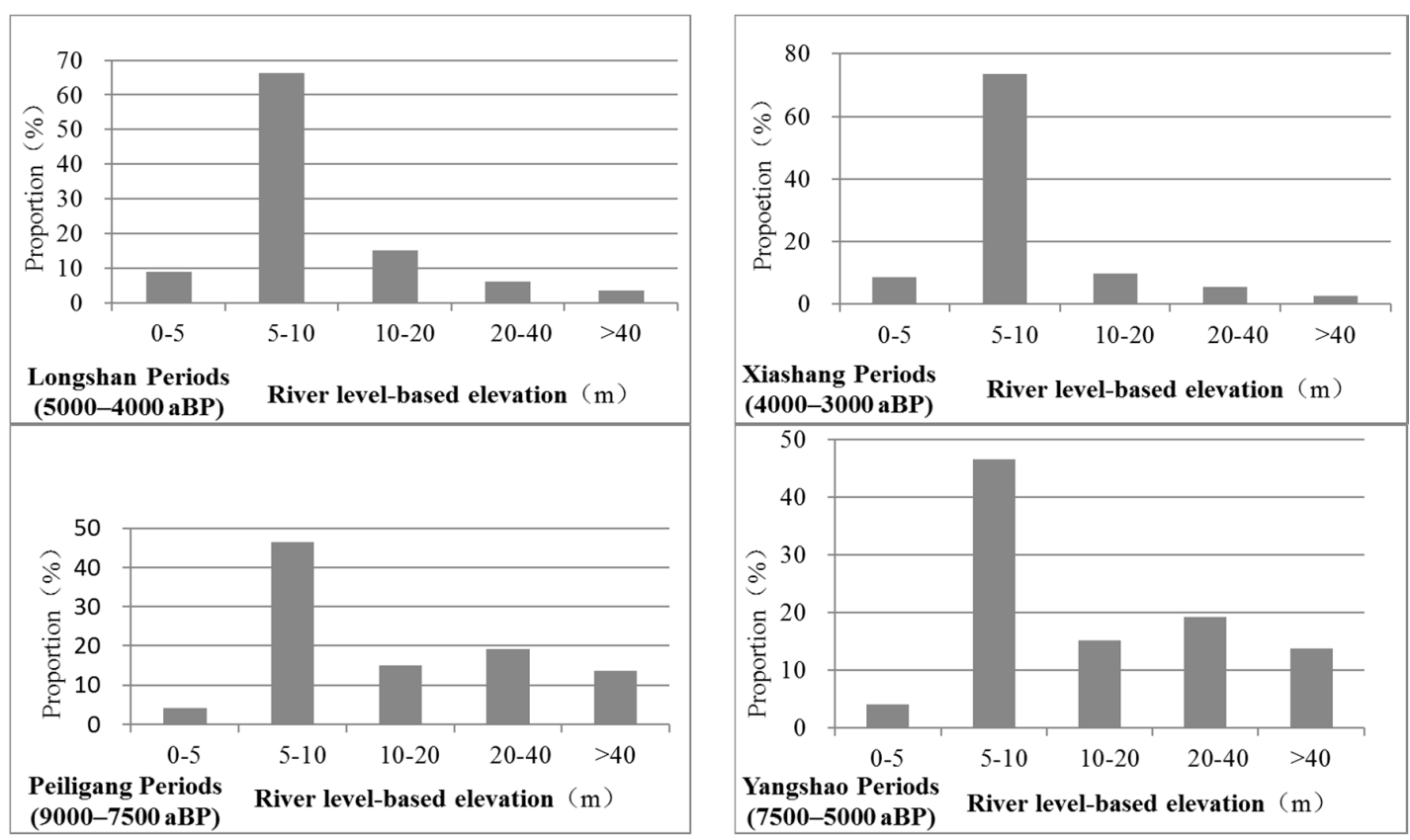

Figure 6. River level-based elevation of prehistoric settlements around Songshan Mountain.

In summary, the distribution of the settlements with respect to elevation above the river levels (see Table 3 and Figure 7) show that the higher percentage for all the historical periods is related to $5-10 \mathrm{~m}$. This percentage increased constantly over time from $47.2 \%$ related to the most ancient (Peiligang) up to $73.7 \%$ for the most recent period (Xiashang). The second higher percentage was related to elevations above the river levels from 10 to $20 \mathrm{~m}$, characterized by an oscillating trend ranging from $9.8 \%$ to $21.7 \%$. A decreasing trend characterized the percentage of the settlements located above $20-40 \mathrm{~m}$ and higher than $40 \mathrm{~m}$.

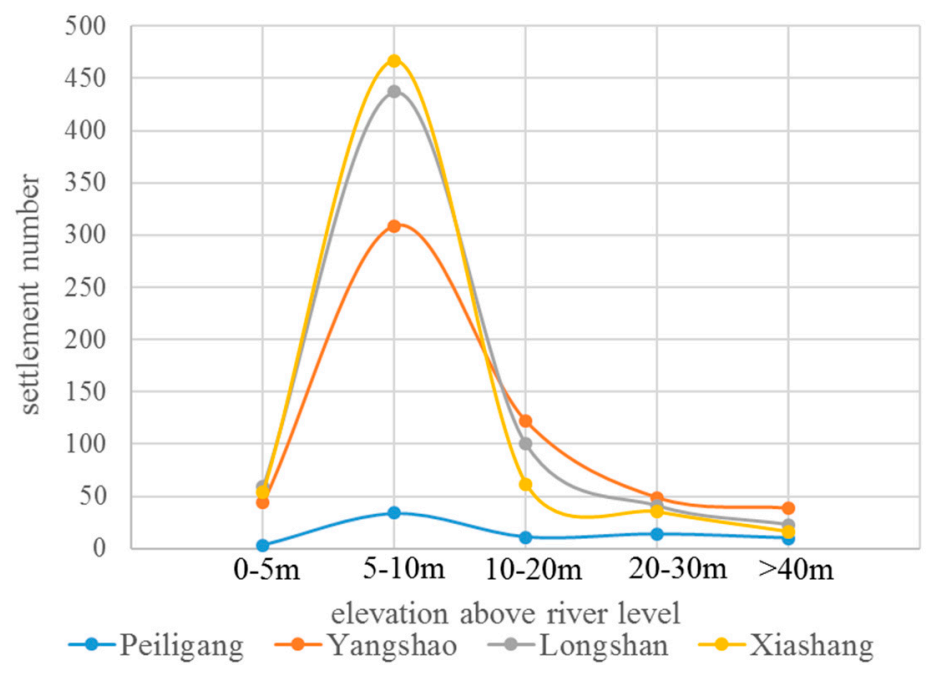

Figure 7. Settlement distribution as a function of elevation above river levels over tine: from Peiligang (9000-7500 aBP) to Xiashang (4000-3000 aBP) Culture.

As a whole, the results implied that the settlements favored the hilly lands, as expected, because of alternating downcutting and sedimentation events. 


\subsection{Discussion}

Landform plays a fundamental role in settlement site selection. Terrain fluctuation and height, resources type and abundance, and the distance to water sources all have a significant impact on the distribution pattern of prehistoric settlements [38-43]. As shown by the data, most settlements were located at an elevation above the river levels in the range of 5-20 m (see Table 3, Figures 6 and 7). This elevation corresponded to low mountains and hills in the upper reaches. There are many low mountains and hills in the Songshan Mountain area. These low hills were generally block mountains and block hills with overall uplifting. Although the terrain is high, the top is quite flat, which facilitates the deposition and preservation of Quaternary loess [44]. This terrain feature is favorable for the construction of settlements, engagement in production activities, access to river resources and limiting flood risks. Central China represented by the Songshan Mountain area is known for its high cultural continuity and unity. One of the major reasons for this feature is the effective utilization of low mountains and hills, which guaranteed the continuity of regional culture for thousands of years.

As shown by the statistical results, site selection of prehistoric settlements around Songshan Mountain had the following evolutionary features. (1) In the Peiligang period, relatively few settlements were distributed on the plain, but they still accounted for the largest proportion compared with the three other periods. On a larger spatial scale covering Central China, the number of settlements on the plain in the Peiligang period was quite large [10]. Among the settlements in mountainous region and hilly lands, high-elevation settlements were very few. This indicated that the settlements in the Peiligang period were mainly distributed in hilly lands having lower elevation above river level. Accordingly, settlements in the Peiligang period can be roughly divided into those on hilly lands and those on the plain; (2) During the Yangshao period the sites of settlements were mainly in the mountainous region and in hilly lands. Nearly $95 \%$ of settlements were distributed in the mountainous region and hilly lands in this period. Even within Henan province, settlements in the Yangshao period were mostly distributed in the mountainous region and hilly lands, especially in the loess hilly region in western Henan. Compared with the Peiligang period, the number of high-elevation settlements was considerably greater, with the maximum elevation above the river levels exceeding $300 \mathrm{~m}$; (3) Similar to the Yangshao period, the Longshan culture also tended to select settlement sites in the mountainous region and hilly lands. The proportion of settlements located in the mountainous region and hilly lands as well as the maximum elevation above river levels were comparable to those in the Yangshao period; (4) In the Xiashang period, the number and proportion of settlements distributed in the mountainous region and hilly lands remained high, while the number of settlements distributed on the plain increased considerably compared with the Yangshao and Longshan periods.

With regard to the level of settlements with respect to the river, the higher percentage was related to $5-10 \mathrm{~m}$. This percentage increased constantly over time from the Peiligang to Xhiashang ages. On the contrary, the percentage of the settlements located above $20 \mathrm{~m}$ exhibited a decreasing trend over time.

In terms of size and grade [45], the high-grade settlements such as capital towns and large-scale settlements tended to be distributed on the plain in Xiashang period. Those distributed in the mountainous region and hilly lands were mostly low-grade, small size settlements. Moreover, the settlements distributed in the mountainous region and hilly lands in the Xiashang period were mostly superposed settlements coexisting with cultural relics from the three other periods. Most settlements on the plain only contained a sort of cultural relics of the Xiashang period [46]. Although the Xiashang settlements were also located mainly in the mountainous region and hilly lands, the idea of site selection had transformed to the establishment of large-scale settlements in the plain area.

Therefore, the site selection mode of neolithic settlements in the Songshan Mountain area can be summarized as follows. In the Peiligang period, settlements were established on the plain and in the mountainous region and hilly lands. During the Yangshao and Longshan cultures, people mainly settled in the mountainous region and hilly lands. Finally, in the Xiashang period, a migration of people to the plain area took place, in particular around Luoyang and Zheng Zhou. 
The distribution and evolution of prehistoric settlements in the Songshan Mountain area were not only related to the environment, but also to cultural development. It has been shown that agricultural activities had already appeared in the Peiligang period [47], but such activities took up a very small proportion of all production activities [48]. The production modes also varied from one area to another. Unearthed relics revealed that the main production mode in settlements in hilly lands was a combination of dry land farming with collection and hunting. Carbonized maize grains were discovered in the Shawoli site [49]. The animal bones were mainly from land animals such as cows, sheep, pigs and dogs. There were basically no aquatic animals [50,51]. In settlements of the plain area, the production mode was a combination of rice agriculture with collection and hunting. The relics included carbonized rice grains, wild water chestnuts, fish and mussels [52]. This indicated that the demand for land or aquatic resources and the production mode of dry farming or rice agriculture were the major reasons for the two settlement types of near-mountain terraces and near-water terraces in the Peiligang period. In the Yangshao and Longshan periods, the largest number of settlements was located in the low hills. In these periods, agricultural production had become the major activity, although collection, fishing and hunting still comprised a portion of production activities.

In the Xiashang period, the social structure and composition changed, then very large settlements appeared [45]. In this context, the reason why many settlements were still distributed in the mountainous region and hilly lands appears to be the influence of tradition. There were few settlements related to new foundations in the mountainous region and hilly lands whereas the majority was composed by settlements containing a variety of cultural accumulation [46]. Moreover, due to the geomorphic conditions, more large-grade and large-scale settlements were constructed in the plain area, which was more suitable for large-scale agricultural production, rather than in the fragmented, small-area mountainous region and hilly lands.

The distribution of prehistoric settlements and the evolution of fluvial landforms in the Songshan Mountain area indicated that the natural environment was fundamental in the interaction between prehistoric humans and nature. In this process, human beings actively chose the most appropriate natural conditions in which to live and carry out production activities according to their mode of life and production, social structures and cultural traditions.

\section{Conclusions}

(1) The features of fluvial landforms in the early and middle Holocene in the Songshan Mountain area were much different from today. In the middle Holocene (8500-3000 aBP), the Songshan Mountain area experienced large-scale sedimentation, with river levels generally higher than today's levels. In the late Holocene (after $3000 \mathrm{aBP}$ ), the mountainous region and hilly lands in the upper and middle reaches began to experience river downcutting, while the lower reaches experienced continuous sedimentation.

(2) Selection of prehistoric settlement sites in the Songshan Mountain area evolved over time. In the Peiligang period, settlements were constructed in both the elevated terrain (mountainous region and hilly lands) and on the plain, depending on the production mode. In the Yangshao and Longshan periods, settlements were mainly distributed in the mountainous region and hilly lands. In the Xiashang period, the percentage of settlements established on the plain tended to increase respect to the past periods.

(3) The low hills and hilly lands with elevations above river levels of 5-20 m consistently had the largest number and highest density of prehistoric settlements in the Songshan Mountain area. The long-term, effective utilization of low hills and hilly lands that were widely distributed with flat tops and a loess layer insured the continuity of local culture for thousands of years.

(4) Study of the distribution of prehistoric settlements and the evolution of fluvial landforms indicates that the environment plays a fundamental role in interactions between prehistoric humans and nature. In the process, human beings always selected the land with the most appropriate natural conditions to live according to their own cultural features. 
(5) In the future, further improvements, aimed at a deeper quantitative analysis, can be obtained by means of an integrated use of different remote sensing data, including multispectral, SAR and historical archived images [53-55], by adopting specific models and spatial analyses.

Acknowledgments: The study is funded by the National Natural Science Foundation of China (Grant No. 41671014, 41201414), the Major Program of the National Social Science Foundation of China (Grant No. 11\&ZD183 and the Major Project of Songshan Mountain Culture Research Society).

Author Contributions: Peng Lu and Duowen Mo conceived and designed the study. Hui Wang, Ruixia Yang, Yan Tian and Panpan Chen performed the experiments. Peng Lu wrote the paper. Rosa Lasaponara and Nicola Masini reviewed and edited the manuscript. All authors read and approved the manuscript.

Conflicts of Interest: The authors declare there is no conflicts of interest regarding the publication of this paper.

\section{References}

1. Trigger, B.G. Time and Tradition: Essays in Archeological Interpretation; Edinburgh University Press: Edinburgh, UK, 1978.

2. Chang, K.C. Settlement Archaeology; National Press Books: Palo Alto, CA, USA, 1968.

3. Russell Stafford, C.; Creasman, S.D. The hidden record: Late Holocene landscapes and settlement archaeology in the Lower Ohio River Valley. Geoarchaeology 2002, 17, 117-140. [CrossRef]

4. Hu, K.; Mo, D.W.; Mao, L.J.; Li, S.C.; Wang, H.; Cao, W.; Zhang, Y.F. Spatial analysis and landscape significance of mankind settlement sites in Wuding River Basin in Mid-Holocene. Sci. Geogr. Sin. 2011, 31, 415-420. (In Chinese)

5. Lu, P. Review on prehistoric settlement geography research. Prog. Geogr. 2013, 32, 1286-1295. (In Chinese)

6. Potter, T.W. Valleys and Settlement: Some New Evidence. World Archaeol. 2003, 8, 207-219. [CrossRef]

7. Yan, L.J.; Shi, Y.S.; Yang, R.X.; Lu, P. Prehistoric settlement sites selection preference zoning around Songshan Area. J. Tongji Univ. (Nat. Sci.) 2013, 41, 624-629. (In Chinese)

8. Yang, R.X.; Lu, P.; Wu, H.H. The analysis of spacial centralized character of settlements at Peiligang Culture Period in Henan Province. Areal Res. Dev. 2012, 31, 150-155. (In Chinese)

9. East, A.E.; Collins, B.D.; Sankey, J.B.; Corbett, S.C.; Fairley, H.C.; Caster, J. Conditions and Processes Affecting Sand Resources at Archaeological Sites in the Colorado River Corridor Below Glen Canyon Dam, Arizona; US Geological Survey Professional Paper 1825; U.S. Geological Survey: Reston, VA, USA, 2016; p. 104.

10. Balsom, J.R.; Ellis, J.G.; Horn, A.; Leap, L.M. Using cultural resources as part of the plan-Grand Canyon management and implications for resource preservation. In The Colorado Plateau II-Biophysical, Socioeconomic, and Cultural Research: Tucson; van Riper, C., III, Mattson, D.J., Eds.; University of Arizona Press: Tucson, AZ, USA, 2005; pp. 367-377.

11. Fairley, H.C. Cultural resources in the Colorado River corridor. In The State of the Colorado River Ecosystem in Grand Canyon; Gloss, S.P., Lovich, J.E., Melis, T.S., Eds.; U.S. Geological Survey Circular 1282; Grand Canyon Monitoring and Research Center: Flagstaff, AZ, USA, 2005; pp. 177-192.

12. Davis, W.M. The geographical cycle. Geogr. J. 1899, 14, 481-504. [CrossRef]

13. Yang, J.C.; Li, Y.L. Principle of Geomorphology; Peking University Press: Beijing, China, 2001. (In Chinese)

14. Lu, P.; Yang, R.X. Summarizing the prehistoric settlement in the digital environment archaeology. Areal Res. Dev. 2013, 32, 165-169. (In Chinese)

15. Danese, M.; Masini, N.; Biscione, M.; Lasaponara, R. Predictive modeling for preventive Archaeology: Overview and case study. Cent. Eur. J. Geosci. 2014, 6, 42-55. [CrossRef]

16. Zhang, D.S. The characteristics of civilization origin in Central China. Huaxia Archaeol. 2002, 4, 48-53. (In Chinese)

17. Zhou, K.S. Environmental Archaeology; Cultural Relics Publishing House: Beijing, China, 2007. (In Chinese)

18. Zhou, K.S.; Zhang, S.L.; Zhang, Z.Y.; Yang, R.X.; Cai, Q.F.; Song, G.D.; Song, Y.Q.; Mo, D.W.; Wang, H.; Lu, P.; et al. Songshan Cultural Circle. Cult. Relics Cent. China 2005, 5, 12-20. (In Chinese)

19. Wang, W.K. Henan Geography; Henan People's Publishing House: Zhengzhou, China, 1990. (In Chinese)

20. Huang, C.C.; Pang, J.L.; Zha, X.C.; Su, H.X.; Jia, Y.F. Extraordinary floods related to the climatic event at $4200 \mathrm{aBP}$ on the Qishuihe River, middle reaches of the Yellow River, China. Quat. Sci. Rev. 2011, 30, 460-468. [CrossRef] 
21. Shi, Z.M. The Natural Conditions and Resources of Henan Province; Science and Technology Press: Zhengzhou, China, 1986. (In Chinese)

22. Institute of Archaeology, Chinese Academy of Social Sciences. Chinese Archaeology (Xia and Shang Volume); China Social Sciences Publishing House: Beijing, China, 2003. (In Chinese)

23. Institute of Archaeology, Chinese Academy of Social Sciences. Chinese Archaeology (Neolithic Volume); China Social Sciences Publishing House: Beijing, China, 2010. (In Chinese)

24. Henan Bureau of Geology and Mineral Resources. Areal Geology of Henan Province; Geological Publishing House: Beijing, China, 1989. (In Chinese)

25. Lu, P.; Tian, Y.; Chen, P.P.; Mo, D.W. Spatial and temporal modes of prehistoric settlement distribution around Songshan Mountain. Acta Geogr. Sin. 2016, 71, 1629-1639. (In Chinese)

26. Henan Province Administration of Cultural Heritage. Cultural Heritage Chronicles of Henan Province; Cultural Relics Press: Beijing, China, 2009. (In Chinese)

27. Zhou, K.S.; Zhang, S.L.; Mo, D.W.; Wang, H. Environment and culture during the latest middle Pleistocene-early late Pleistocene in the Mountain Song region, Henan Province. Quat. Sci. 2006, 26, 543-547. (In Chinese)

28. Xu, J.J.; Mo, D.W.; Wang, H.; Zhou, K.S. Preliminary research of environment archaeology in Zhenshui River, Xinmi City, Henan. Quat. Sci. 2013, 33, 981-991. (In Chinese)

29. Chengdu Geology College. Sedimentary Rock Particle Size Analysis and Its Application; Geological Publishing House: Beijing, China, 1978. (In Chinese)

30. Wang, H. Exploration of the relationship between neolithic settlement distribution and natural environment in the middle-upper Shuangjihe River. In Science and Technology Archaeology (Album 2); Archaeological Center of Science and Technology, Institute of Archaeology, Chinese Academy of Social Sciences, Ed.; Science Press: Beijing, China, 2007; pp. 141-154. (In Chinese)

31. Dong, G.H.; Xia, Z.K.; Liu, D.C.; Wu, Q.L. Environmental change and its impact on human activities in Middle Holocene at Mengjin, Henan Province. Acta Sci. Nat. Univ. Pekin. 2006, 42, 238-243. (In Chinese)

32. Sun, X.W.; Xia, Z.K. Paleoenvironment Changes since Mid-Holocene Revealed by a Palynological Sequence from Sihenan Profile in Luoyang, Henan Province. Acta Sci. Nat. Univ. Pekin. 2005, 41, 289-298. (In Chinese)

33. Wang, D.F.; Wang, C.; Wang, C.D.; Guo, Y.S. Lake Yuxingze, a natural flood detention area of the Yellow River in ancient time. J. Lake Sci. 2012, 24, 320-326. (In Chinese)

34. Xia, Z.K.; Wang, Z.H.; Zhao, C.Q. Extreme flood events and climate change around 3500 aBP in the Central Plains of China. Sci. China Ser. D Earth Sci. 2004, 47, 599-606. [CrossRef]

35. Wang, H.; Zhang, H.; Zhang, J.F.; Fang, Y.M. The fluvial geomorphology evolution and some relevant question of Wadian Site in Yuzhou City, Henan Province. South. Cult. Relics 2015, 4, 67-77. (In Chinese)

36. Wan, Y.; Liu, Y.; Shi, Z.T. Structure and characteristics of geomorphology in the area between Huanghe River and Luohe River in Henan Province. J. Lanzhou Univ. (Nat. Sci.) 2010, 46, 40-47. (In Chinese)

37. Yan, F.H.; Mai, X.S.; Ye, Y.Y. Geological ace and environment of the Dahecun Site, Zhengzhou, from sporo-poilen data. Seismol. Geol. 1986, 8, 69-74. (In Chinese)

38. Dillehay, T.D. Climate and human migrations. Science 2002, 298, 764-765. [CrossRef] [PubMed]

39. Howard, A.J.; Brown, A.G.; Carey, C.J.; Challis, K. Archaeological resource modeling intemperate river valleys: A case study from the Trent Valley, UK. Antiquity 2008, 82, 1040-1054. [CrossRef]

40. Nunez, L.; Grosjean, M.; Cartajena, I. Human occupations and climate change in the Puna de Atacama, Chile. Science 2002, 298, 821-824. [CrossRef] [PubMed]

41. Tristram, R.K.; Katherine, A.A.; Lee, J.; Schilling, T.M. Basin scale reconstruction of the geological context of human settlement: An example from the lower Mississippi Valley, USA. Quat. Sci. Rev. 2008, 27, 1255-1270.

42. Walker, I.J.; Desloges, J.R.; Crawford, G.W.; Smith, D.G. Floodplain formation processes and archaeological implications at the Grand Banks Site, lower Grand River, Southern, Ontario. Geoarchaeology 1997, 12, 865-887. [CrossRef]

43. Wilkinson, T.J. Water and human settlement in the Balikh Valley, Syria: Investigations from 1992-1995. J. Field Archaeol. 1998, 25, 63-87. [CrossRef]

44. Lu, P.; Tian, Y.; Chen, P.P.; Yan, L.J.; Song, L.S. The relationship between settlements distribution and regional tectonics around the Songshan Mountain during 9000-3000 aBP. Acta Geogr. Sin. 2014, 69, 738-746. (In Chinese) 
45. Lu, P.; Tian, Y.; Yang, R.X. The study of size-grade of prehistoric settlement in the Circum-Songshan area based on SOFM network. J. Geogr. Sci. 2013, 23, 538-548. [CrossRef]

46. Lu, P.; Tian, Y. The successive mode of 9000-3000 aB.P. settlements and its relationship with the terrain around Songshan Mountain. Quat. Sci. 2013, 33, 965-971. (In Chinese)

47. Liu, L.; Lee, G.A.; Jiang, L.P.; Zhang, J. Evidence for the early beginning (c. 9000cal. BP) of rice domestication in China: A response. Holocene 2007, 17, 1059-1068. [CrossRef]

48. Zhao, Z.J. Plant archaeology research about agriculture origin and civilization origin. Manag. Rev. Soc. Sci. 2005, 2, 82-91. (In Chinese)

49. Institute of Archaeology, Chinese Academy of Social Sciences. The Shawoli Neolith Site in Xinzheng, Henan. Archaeology 1983, 12, 1057-1065. (In Chinese)

50. Wang, H.J. The carbonization grain was found in Shawoli Site, Xinzheng. Agric. Archaeol. 1984, 2, $276-277$. (In Chinese)

51. Zhang, Y.H.; Weng, Y.; Yao, L.; Zhang, J.Z.; Zhou, M.J.; Fang, F.; Cui, W. Identification and analysis of starch granules on the surface of the slabs from Peiligang Site. Quat. Sci. 2011, 31, 891-899. (In Chinese)

52. $\mathrm{Xu}$, T.S. The original agriculture during the Peiligang Period. Cult. Relics Cent. China 1998, 3, $12-23$. (In Chinese)

53. Lasaponara, R.; Leucci, G.; Masini, N.; Persico, R.; Scardozzi, G. Towards an operative use of remote sensing for exploring the past using satellite data: The case study of Hierapolis (Turkey). Remote Sens. Environ. 2016, 174, 148-164. [CrossRef]

54. Lasaponara, R.; Masini, N. Satellite Synthetic Aperture Radar in Archaeology and Cultural Landscape: An Overview. Archaeol. Prospect. 2013, 20, 71-78. [CrossRef]

55. Lu, P.; Yang, R.; Guo, Y.; Chen, F.; Masini, N.; Lasaponara, R. On the use of historical archive of aerial photographs for the discovery and interpretation of ancient hidden linear cultural relics in the alluvial plain of eastern Henan, China. J. Cult. Herit. 2016. [CrossRef]

(C) 2017 by the authors; licensee MDPI, Basel, Switzerland. This article is an open access article distributed under the terms and conditions of the Creative Commons Attribution (CC-BY) license (http://creativecommons.org/licenses/by/4.0/). 